\title{
Några erfarenheter \\ från en svensk övervakningsnämnd
}

\author{
Av häradshövding ERNST LECHE
}

\section{Organisation}

Den 31 december 1964 gick den då hundraåriga och söndervittrade svenska strafflagen i graven och följdes av det stora lagverket brottsbalken. I samband därmed tillkom en ny institution inom ramen för straffrättskipningen — nämligen övervakningsnämnden. Sådana nämnder - vilka är spridda över hela landet — hade alltså vid det senaste årsskiftet varit verksamma i fem år. I det följande skall här i stora drag skildras arbetet och vunna erfarenheter under dessa år i en övervakningsnämnd (övnd) av normal struktur.

Övndn är avsedd att vara ett väsentligt organ för kriminalvården $\mathrm{i}$ frihet och skall leda vården $\mathrm{i}$ vidsträckt mening inom sitt verksamhetsområde. Klientelet utgöres inte endast av dem som omedelbart dömts till frivård i form av skyddstillsyn. Lika stor omsorg skall övndn ägna dem som efter en viss tids frihetsberövande friges villkorligt eller utskrives för vård utom anstalt.

En övnd består i regel av fem ledamöter. Ordföranden och hans ersättare är jurister och skall ha erfarenhet av dömande verksamhet. De utses av regeringen för fem år. Samma tjänstgöringstid gäller för de övriga ledamöterna vilka jämte suppleanter utses av länsstyrelsen i det län där övndn är verksam. Önskemålet är att dessa ledamöter — som undantagslöst är lekmän — skall ha erfarenhet av ungdomsvård och arbetsförmedling eller eljest i allmänna värv.

Verksamhetsområdet för den övnd varom här är fråga omfattade tre tämligen vidsträckta domkretsar. I nämnden tjänstgjorde under femårsperioden en läkare, en tjänstman i arbetsmarknadsverket, en kvinnlig ledamot med erfarenhet från skolväsendet tillika gymnastikdirektör och leg. sjukgymnast - samt en ledamot med mångårig kommunal verksamhet på både läns- och lokalplanet. Sistnämnda två ledamöter hade tillika i egenskap av nämndemän erfarenhet av rättskipningen. Flera av suppleanterna — vilka ofta var inkallade till tjänstgöring — hade länge varit verksamma inom ungdomsarbete eller yrkesskolväsendet. Några suppleanter - därav en kvinna - var dessutom nämndemän i domstol i orten.

Övndn sammanträdde mycket ofta allt efter behov och i regel i en ort som låg bäst till för klientelet. Som lokal användes aldrig 
domssalarna i tingshusen. Man strävade nämligen efter att få en så otvungen miljö som möjligt för att klienterna skulle känna sig obesvärade och förmås att tala fritt och otvunget.

Till hjälp i arbetet hade övndn befattningshavarna hos statens skyddskonsulentorganisation - i det följande kallad frivården. Utan tvekan står och faller en övnds verksamhet med insatserna av dessa befattningshavare (skyddskonsulent, biträdande skyddskonsulent och skyddsassistent). Väsentligen genom deras insatser och osparda möda och negligerande av den författningsreglerade tjänstetiden kunde denna övnd fylla sin uppgift. Ordföranden och sekreteraren stod i ständig förbindelse med frivården vid personliga sammanträffanden eller per telefon. Särskilt betydelsefullt var att ordföranden därigenom fick tillfälle att mellan sammanträdena överlägga med vederbörande tjänsteman inför brådskande eller mera ingripande beslut. Samarbetet mellan övndn och frivården var under hela verksamhetsperioden mycket gott och präglades av en ömsesidig strävan att göra det bästa möjliga för klientelet.

Inom övndns verksamhetsområde fanns en nyuppförd kriminalvårdsanstalt — som här kan benämnas ölunda - med plats för sextio interner. Den var i viss utsträckning utslussningsanstalt för en större sluten anstalt.

\section{Den villkorliga frigivningen}

En övnd skall pröva frågan om villkorlig frigivning av dem som dömts till fängelse högst ett år och avtjänat minst fyra månader. Motsvarande frigivning av dem som dömts till längre frihetsstraff än ett år ankommer på den centrala kriminalvårdsnämnden i Stockholm. Innan denna beslutar avger dock den lokala övndn yttrande efter utredning i ärendet.

När tiden för den villkorliga frigivningen nalkades började den förberedas av frivården och föreståndaren på ölunda - ofta i samråd med en kontaktman hos länsarbetsnämnden i residensstaden i länet. Tre ting måste ordnas: arbete, bostad och övervakare. Frigivningen skedde aldrig slentrianmässigt eller på en slump. I propagandan mot den svenska kriminalvården har det ofta sagts att då en frigiven går från en anstalt lämnas han mer eller mindre vind för våg. Han står utan arbete och bostad och med ett löjligt litet belopp på fickan. Kritikerna menar att i den situationen är det bäddat för fortsatt asocialitet och brottslighet. Det förtjänar då nämnas att under ifrågavarande femårsperiod frigav denna övnd icke en enda intern utan att övndn först förvissat sig om att han hade arbete eller i varje fall arbetsmöjlighet, likaväl som tak över huvudet. Att den frigivne sedan struntade i planerat eller erbjudet arbete och omedelbart efter frigivningen 
misskötte sig är en annan sak. Härtill finns anledning att återkomma.

Vid ett sammanträde några veckor före den planenliga frigivningen fick internen träffa övndn. Man satt då tillsammans vid ett långbord - hela övndn, en eller två tjänstemän från frivården, föreståndaren på anstalten och internen själv. Någon gång var även kriminalvårdsdirektören och frivårdsinspektören $\mathrm{i}$ räjongen samt en anstaltspsykolog närvarande. Efter föredragning av det väsentliga av internens föregående och den aktuella brottsligheten kompletterades bilden under formlöst samspråk. Övndn hade ofta anledning att beklaga den torftighet som utmärkte den dom som fört en intern till anstalten. Hans person och de närmare omständigheterna omkring brottet - något som kunde ha varit vägledande för övndn — skildrades i regel i domarna i schabloner eller intetsägande fraser.

Efter denna inledande uppmjukning tog man upp den väsentliga frågan eller vad som nu närmast skulle ske. Internen fick klart för sig att denna övnd icke ställde honom försvarslös på gatan. De förutsättningar för den villkorliga frigivningen som nämnts i det föregående måste alltså föreligga för att han skulle „få gå “ som den i dessa kretsar vedertagna termen lyder. Detta sade sig internen förstå eller i varje fall låtsades han förstå detlåt vara ibland litet surmulet. Hade övndn icke vetat det förut dröjde det inte länge efter det den börjat sin verksamhet förrän den upptäckte, att det knappast torde finnas en större optimist beträffande framtiden än en intern som skall lämna en anstalt. Hur han än misslyckats tidigare med arbetsanställning eller över huvud $\mathrm{i}$ livet - nu om inte förr var stunden kommen då det skulle vända sig till det bättre. Man gjorde inom övndn ibland den reflexionen att framtidsvyernas styrka stod i direkt proportion till vederbörandes kriminella belastning. I sådana situationer gällde det att inte nedslå internens mod genom att visa misstro eller allra minst att vara ironisk. Åtskilliga uppslag som internen kom med måste dock snabbt avföras från vidare diskussion som hugskott. Detta tog internerna aldrig illa upp. Kanske hade en och annan rent av svårt att hålla sig allvarlig när man helt gemytligt under samtalets gång lät alltför diffusa framtidsplaner tona bort i det blå. På samma sätt förhöll det sig när internen kom med muntliga eller skriftliga uppgifter om högst tvivelaktiga arbetsanställningar eller bostadsmöjligheter. En genomskådad bluff av detta slag ledde aldrig till motsättningar mellan internen och övndn utan förhandlingarna kunde fortsätta ostört.

Utgångsläget vid diskussionen om arbetet var som nämnts att kravet i denna del obönhörligen måste vara uppfyllt före frigivningen. I annat fall fick internen stanna $\mathrm{i}$ anstalten tillsvidare. Denna fasta hållning från övndns sida respekterades uppenbar- 
ligen; i varje fall hördes aldrig några missnöjesyttringar av denna anledning. Kanske berodde det på att - enligt vad övndn under hand erfor - internerna på ölunda kände till att ingen möda lämnades ospard då det gällde att skaffa fram ett lämpligt arbete. När detta lyckades tillkom äran i regel frivårdens tjänstemän - även om äran någon gång fick delas med föreståndaren på ölunda eller kontaktmannen hos länsarbetsvården. En och annan gång deltog ordföranden eller någon ledamot i övndn själva i ,operation övertalning“ för att förmå en mindre villig presumtiv arbetsgivare att taga sig an en viss svårplacerad klient. Inte sällan hände det att den ledamot som tillhörde arbetsmarknadsverket under pågående sammanträde ringde runt i landet och till slut fick fram ett arbete som både övndn och internen kunde godtaga. Samme ledamot kunde med sin ingående kännedom både om gällande författningebestämmelser och dagsläget på arbetsmarknaden tillbakavisa ovederhäftiga invändingar av internen. Någon enstaka gång avböjdes hjälp i arbetsmarknadsverkets regi - man förklarade sig „leds“" på sådant arbete.

I svenska massmedia klandras ofta samhället - närmast företrätt av arbetsgivarna - för att man inte vill räcka den frigivne fången en hjälpande hand då han kommer ut. Man menar att hallstämpeln ,förbrytare“ sällan eller aldrig går att få bort. Denna övnd fick dock den uppfattningen att detta var en överdrift såvitt angick dess klientel. Tvärtom såg man inom den privata sektorn mycket litet av denna fördom. Men när den någon gång förekom hade den ofta en rätt naturlig förklaring. En orsak kunde vara att arbetsgivaren var ,bränd“ efter ackvisitionen från övndns sida; arbetskraft som han tidigare tagit emot hade vållat honom besvikelse eller direkta svårigheter. En annan invändning som mötte var att de anställda hotade med arbetsnedläggelse om en viss intern anställdes - inte för att han var straffad utan för att han vid en föregående anställning hos företaget varit arbetsovillig eller stört arbetet genom prat eller på annat sätt.

Med hänsyn till att övndns klientel av olika anledningar inte alltid var en alltför eftersökt arbetskraft blev många gånger en s k skyddad verkstad eller en omskolningskurs en räddningsplanka. Tyvärr var detta stundom en galgenfrist. Man insåg att problemet med den frigivnes framtid skulle antagligen komma igen längre fram men då måste det bli andra sociala organ som fick taga ansvaret. Om det inte rent av blev en ny tur inom kriminalvården. Att välviljan hos omskolningskursernas ledning att taga emot övndns klientel understundom kunde vara litet reserverad berodde naturligt nog på att man måste se till att kursernas standard och ordningsförhållandena där inte påverkades i negativ riktning genom tillskottet från kriminalvården. En ytterligare placeringsmöjlighet var arbetsmarknadsverkets arbetsläger 
där för den relativt skötsamme rimliga bostads- och inkomstmöjligheter stod till buds. I detta fall gällde det $\mathrm{i}$ regel socialt snedbelastat klientel.

När övndn och dess medarbetare körde ohjälpligt fast i sina strävanden att skaffa fram ett lämpligt arbete till dagen för frigivningen kunde övndn ibland lita till internens egna försök att nå ett resultat. Han erhöll således permission några dagar för att på egen hand söka komma i förbindelse med en arbetsgivare. Förbluffande nog ledde detta inte sällan till framgång. I dessa fall var övndn tämligen diskret och inskränkte sig till att se till att några allvarligare erinringar inte kunde göras mot den tilltänkta anställningen.

För genomsnittsmänniskan är arbetet inte endast något som ger bröd för dagen. Det är även en väsenlig förutsättning för att man skall hålla sig i form fysiskt och psykiskt. Internerna på Ölunda såg inte alla gånger saken så. Många var direkt arbetsskygga men hycklade arbetsvillighet inför övndn. Detta hade övndn klart för sig men måste ändå hålla god min när man ofta med stort besvär - lyckats ordna med ett arbete. De som inte var direkt arbetsskygga var dock utpräglade sangviniker. De kunde blossa upp och bli entusiastiska inför ett arbetsprojekt. Att de ömsesidiga förhoppningarna sedan inte slog in kunde frivården inte lastas för - och inte samhället i gemen. En till synes ödesbestämd väg låg — kanske för ett årtionde eller mera ändå utstakad.

Då övndn satt och diskuterade den förestående frigivningen med internen var en återkommande replik på frågan varför han misslyckats med tidigare anställningar ,att nog kunde han sköta ett arbete bara han fick något som han trivdes med". När man sedan frågade vilket arbete han skulle kunna tänkas trivas med blev svaret undantagslöst mycket svävande. Övndn fick det intrycket att detta var ett spörsmål som vederbörande aldrig tagit ställning till.

Att en kriminellt belastad eller på annat sätt socialt nedgången intern inte ville eller kunde binda sig vid ett bestämt och ordnat arbete hade övndn förståelse för. En sådan intern hade tydligen kommit därhän att han inte kunde stå vid maskinen på ett verkstadsgolv - att komma och gå efter en stämpelklocka - att hugg $\mathrm{i}$ med ett rejält grovarbete - eller att överhuvud bli en kugge i samhällsmaskineriet. Därför gjorde många interner undanglidningar när arbetsfrågan kom på tal. Eller de nickade god mening eller bluffade genom att visa ett övertygande positivt intresse. Någon gång saboterades en av övndn ordnad testning för tilltänkt omskolning. En man som med hänsyn till sin tidigare verksamhet med säkerhet kunde beräknas klara ett sådant testprov erkände vid en senare lagföring för nya brott att han 
avsiktligt saboterat proven för att undgå villkorlig frigivning med åtföljande frivård.

Andra besvikelser i detta hänseende förtjänar nämnas eftersom de till sin art inte är ovanliga inom frivărden. För en trettioårig ogift man $\mathrm{A}$ med en allvarlig kriminell belastning blev det klart med en av honom själv önskad anställning som kommunalarbetare $\mathrm{i}$ en mindre stad. I avbidan på att en permanent bostad hann ordnas erbjöds A på stadens bekostnad logi på ett mycket bra pensionat. A infann sig dock inte enligt avtal i staden. Ett par dagar efter A:s frigivning rymde en annan intern från anstalten och - tydligen efter en på förhand uppgjord plan gjorde båda på natten en kassaskåpssprängning men greps $\mathrm{i}$ en trafikkontroll tidigt följande morgon. Åt en annan intern B hade man i en industri i orten skaffat anställning med avtalsenlig lön och bra bostad. För säkerhets skull hade frigivningen bestämts med utgångspunkt från att platsen skulle tillträdas en viss dag. Bakom ryggen på övervakaren och frivården utverkade emellertid $\mathrm{B}$ hos en förman att anställningen skulle få börja med en frivecka. Under denna hann B supa ned sig fullständigt och anställningen gick all världens väg. Det var endast för övndn att förklara den villkorliga friheten förverkad. En tredje frigiven C gick miste om en utlovad anställning genom att han ansåg att på några månaders vistelse på ölunda borde - övervakaren och skyddsorganisationen ovetande - följa några veckors „semester“. Det blev småningom även klart att $\mathrm{C}$ aldrig varit intresserad av anställningen. För händelser av detta slag kan givetvis inte kriminalvården klandras.

För övndn var det uppenbart att av skilda anledningar en inte ringa del av klientelet ej kunde utan vidare inpassas i produktionen eller över huvud var att betrakta som arbetsduglig i det moderna samhället. Nedsatt hälsa och kroppsliga svagheter mer eller mindre som en följd av ett oordnat levnadssätt - eller mental labilitet var därvid framträdande drag. I sådana fall drog sig övndn för att tvinga internen att taga ett arbete som man kunde förespå skulle komma att misskötas. Det var då man ibland måste lita till arbetslägran.

Vad här närmast skildrats hör till de negativa sidorna i övndns arbete för återanpassningen. I rättvisans namn måste det därefter sägas att i det övervägande antalet fall — framför allt då det gällde kriminellt mindre belastade interner — slussades den frigivne in i ett arbete där utvecklingen åtminstone till en början gick i en gynnsam riktning. Även om han inte alltid blev en hundraprocentig tillgång på arbetsplatsen höll han sig dock socialt flytande - och det ansåg övndn vackert så.

Märkligt nog vållade ordnandet av bostad mera sällan övndn besvär. Var internen gift satt i de flesta fall hustrun och väntade 
på honom i familjens bostad. När äktenskapet under strafftiden gâtt till skilsmässa eller hemskillnad blev läget dock besvärligare men nästan alltid gick det ändå att ordna saken. Ungkarlen hade många gånger en kvinna med bostad där han kunde taga in. För åtskilliga unga frigivna stod föräldrahemmet fortfarande öppet. Övndn och dess medhjälpare strävade naturligen efter att söka lösa arbets- och bostadsfrågan så att det kunde bli fråga om vistelse på en och samma ort.

För dem som på ett eller annat sätt har att taga befattning med kriminaliteten och dess yttringar är det notoriskt att ett mycket stort antal lagbrytare är alkoholmissbrukare i olika stadier. Ofta har denna omständighet ställt dem vid sidan i samhället och lagt grunden till deras brottslighet. Efter vad det vill synas har kriminalvårdens kritiker inte ägnat detta förhållande någon större uppmärksamhet. övndn fick med åren en utpräglat negativ inställning till den svenska alkohollagstiftningen. Den fria försäljning som 1955 års rusdrycksförsäljningsreform innebar hade enligt övndns uppfattning medfört att det kriminellt redan belastade eller för brott benägna klientelet kommit i ett avgjort mera utsatt läge än tidigare. Detta återverkar på möjligheterna att skapa gynnsamma förutsättningar för återanpassning efter brott och lagföring. Dessa synpunkter framfördes otaliga gånger vid övndns sammanträden - framför allt vid tillfällen då praktiskt taget varje ärende på föredragningslistan visade sig äga samband med sprit- eller mellanölsmissbruk. Man uttryckte sin förvåning över den ringa klarsyn som statsmakterna och enskilda företrädare för det politiska livet visar när det gäller här åsyftade sociala missförhållanden.

I sin verksamhet drog övndn konsekvenserna av vad den i dessa hänseenden erfor. Då det förelåg ett klart samband mellan en interns alkoholmissbruk och kriminalitet föreskrevs ofta i frigivningsbeslutet att han skulle vara skyldig att underkasta sig den socialmedicinska behandling som skyddskonsulenten i samråd med den lokala nykterhetsnämnden och efter läkarundersökning föreskrev. Att beträffande detta klientel meddela förbud att använda sprit under prövotiden ansåg övndn meningslöst. Ibland föreslog övndn internen att han efter undersökning av anstaltens läkare skulle före frigivningen frivilligt börja en antabuskur. Flere interner gick med härpå men några avböjde antingen utan att ange något skäl eller på grund av föreställningen att en sådan behandling inverkade menligt på den sexuella potensen. I de svårare fallen av alkoholmissbruk och då fråga kunde bli om mera ingripande åtgärder inom ramen för nykterhetsvård översändes frigivningsbeslutet till länsnykterhetsnämnden.

Några penningbekymmer yppade sig sällan vid frigivningen. Snarare framstod det med hänsyn till vad internen intjänat som 
vanskligt att låta honom lämna ölunda med hela beloppet på fickan. I dessa fall fick han ett lämpligt avpassat belopp kontant och resten tillställdes övervakaren att utportioneras i mån av behov. Att ett för stort innehav av pengar kunde bli katastrofalt visade ett fall då en intern — alla ovetande — förfogade över ett par tusen kronor vid frigivningen. En veckas intensivt spritmissbruk med en vittgående gästfrihet ledde till avsked från en av frivården ordnad god anställning.

Vid villkorlig frigivning skall övndn bestämma en prövotid av minst ett och högst tre år. På de flesta håll synes prövotiden slentrianmässigt anges till den kortaste lagstadgade eller ett år. Denna övnd gjorde en prövning i varje särskilt fall och satte icke sällan prövotiden till två år för sădana frigivna vilkas prognos bedömdes som mera vansklig. Det kunảe då hända att vid återfall och ny lagföring den övnd som då hade att vid villkorlig frigivning bestämma prövotid satte denna till allenast ett år trots den ytterligare dokumenterade asocialiteten.

För att frivården skall ha det av lagstiftaren avsedda värdet för den villkorligt frigivne skall han som regel stå under övervakning. Från denna regel gjorde övndn ytterst sällan något undantag. Det förekom t ex för en tidigare icke lagförd äldre man vilken dömts för mened - med fast bostad och en anställning till vilken han omedelbart var välkommen åter.

Valet av övervakare vållade $\mathrm{i}$ de flesta fall inte övndn några större bekymmer. Visserligen var det stundom inte lätt att fả en lämplig övervakare till interner som man på förhand kunde bedöma skulle bli besvärliga men då löstes ofta personvalet sả att någon av övndns ledamöter eller en tjänsteman inom frivården ställde sig till förfogande. Under skrivbordsarbetet vid planeringen av kriminalvården har det framhållits att man bör undvika att förordna polismän till övervakare. Internerna var dock själva många gånger angelägna att få en namngiven polisman i hemorten som övervakare - vanligen den som haft hand om brottsutredningen eller varit vederbörandes övervakare vid tidigare tillfällen. Några gånger hände det att ordföranden skriftligen eller muntligen vände sig till personer som offentligen klandrade kriminalvården med förfrågan om de ställde sig till förfogande som övervakare. I den mån svar ingick var de avböjande.

Som det i det föregående nämnts gick det tyvärr inte alltid bra för den frigivne under prövotiden. Återföll han $\mathrm{i}$ brott upphörde därmed frivårdens befattning med honom. Det var dock vanligare att han utan att begå brott började missköta sig på annat sätt. Han hemföll åt ett avanceret spritmissbruk eller gav ett anvisat arbete på båten. Stundom försvann han helt ur sikte. En befattningshavare inom frivården slog då larm hos ordföranden i 
övndn. Tiden och förhållandena i övrigt medgav i regel inte någon skriftlig framställning i saken utan efter samråd i telefon beslöt ordföranden att den frigivne skulle inställa sig inför övndn eller hämtas dit av polis för att höras om vad som skett. Det vanligaste var att han skulle omhändertagas av den polismyndighet som låg närmast till. Ett sådant beslut — som närmast är att jämställa med häktning - var inte alla gånger lätt att verkställa. Den frigivne måste då efterlysas. Till det sammanträde med övndn som småningom kom att hållas hade inom frivården verkställts en närmare utredning om vad som hänt efter frigivningen. Slutet blev understundom att den villkorliga friheten förklarades förverkad och den frigivne överlämnades till den slutna kriminalvården för att avtjäna återstoden av straffet. Genomgående tog den frigivne detta lugnt - ibland föreföll det rent av som om återförandet till anstalten innebar en lättnad efter en eller annan stormig vecka. En frigiven - som genom ett intensivt festande gått miste om den anställning som ordnats för honom — inledde det förnyade sammanträffandet med övndn med att be om ursäkt för det besvär han förorsakat samt bad att få komma tillbaka till anstalten ,för att man skulle söka skaffa ett nytt arbete åt honom".

Någon gång såg övndn mildare på det inträffade och nöjde sig med att tilldela en varning varefter den frigivne frigavs. Ibland var det nödvändigt att dessutom meddela en föreskrift om den frigivnes fortsatta livsföring $t$ ex $i$ fråga om nykterhetsvård. Det var ju som nämnts där som felet ofta satt när det gick galet.

I viss mån likställda med de villkorligt frigivna var de som dömts till ungdomsfängelse eller internering och utskrivits för vård utom anstalt. De förra var vanskligare än de senare vilka just inte vållade övndn större bekymmer. Förelåg en allvarlig urspåring måste den felande omhändertagas. I dessa fall räckte det i regel inte med en varning utan övndn skrev till ungdomsfängelserespektive interneringsnämnden och föreslog att vården utom anstalt måtte avbrytas och vederbörande återintagas.

Behandlingen av interneringsklientelet krävde ett särskilt handlag för att syftet med vården utom anstalt inte skulle förfelas. Som exempel kan nämnas att klienten D börjat missköta sig och måste inför övndn. Där framstod han som uppriktigt ångerfull och det upplystes att han omedelbart kunde få âtergå till det arbete som han lämnat. Övndn ansåg ingen ytterligare åtgärd från dess sida erforderlig - ej ens en varning - enär enligt skyddskonsulentens uppfattning D:s självkänsla därigenom skulle kunna taga skada och anpassningen försvåras. 


\section{Skyddstillsynen}

Det ojämförligt största klientelet utgjordes av dem som dömts till skyddstillsyn. övndn fick ibland intrycket att domstolarna hyste en påfallande optimistisk tilltro till värdet av och det ändamålsenliga med denna påföljd. Själva föreföll de dömda inte sällan att ha rätt dunkla begrepp om att påföljden innebar något mera än en rent formell reaktion på deras brott. Detta klientel fick övnd se personligen först då vederbörande började att missköta sig mera allvarligt. Att frivårdens tjänstemän såg så mycket mera av dem som dömts till skyddstillsyn och dessutom hade rutinmässiga besvär med åtskilliga av dem är uppenbart men detta ligger utanför denna redogörelse.

Blev bekymren alltför påtagliga och kunde ny brottslighet eller i varje fall ett gravare asocialt levnadssätt befaras trädde övndn i verksamhet. Gången av ett sådant ärande blev i stort sett densamma som då det gällde misskötsamma villkorligt frigivna. Efter en anmälan från frivården - ofta muntligen i telefon eller på ett sammanträde - lät ordföranden kalla eller beslöt låta hämta klienten till ett följande sammanträde eller at han skulle omhändertagas. I det senare fallet förordnades om viss försiktighet vid verkställigheten. Det kunde tänkas att $t$ ex en avbruten kontakt mellan klienten samt övervakaren och frivården enbart berodde på slarv eller nonchalans från den förres sida. Med hänsyn därtill föreskrevs att omhändertagandet inte fick ske utan ytterligare besked, om klienten påträffats under godtagbara bostads- och arbetsförhållanden. Så var dock sällan förhållandet.

Övndns ingripanden framstod ibland som mera effektiva än åklagarmyndighetens. I ett fall fann åklagaren att häktningsskäl inte kunde anses föreligga mot en misskötsam men därjämte för nya brott misstänkt klient och hemställde att klienten måtte omhändertagas av övndn. Detta skedde och ärendet gick sedan tillbaka till åklagarmyndigheten med begären om åtgärd för att få skyddstillsynen undanröjd.

Även vid förhandlingen i skyddstillsynsärendena lämnade en tjänsteman från frivården en skriftlig eller muntlig redogörelse för fallet och klienten fick taga ställning till vad som anförts mot honom och redogöra för sin situation. Ofta var övervakaren och ibland någon anhörig närvarande vid sammanträdet. Den förres ställning var naturligtvis litet ömtålig. Han kunde å ena sidan inte förneka att skyddslingen kommit på sned - t ex börjat missköta sprit och mellanöl eller försummat arbetet. Men å andra sidan ville övervakaren inte framställa saken så att övndn fick intrycket att hans sätt att sköta uppdraget lett till denna beklagliga situation. Detta insåg övndn och undvek att lägga sten på övervakarens ofta a priori tunga börda. Övndn förstod att det 
sannerligen inte alla gånger var lätt att från den ena dagen till den andra - för att inte säga från den ena timman till den andra - hålla en bångstyring yngling under kontroll eller att ge råd och stöd åt den som inte ville ha något av den sorten. Många gånger kröp det fram att övervakaren av egna medel brukat bistå klienten. Även på annat sätt hade praktisk hjälp lämnats en klient D i ett fall som övndn betecknade som ett av de svåraste genom åren. Trots ideliga bakslag och missräkningar hade man i religiös hängivenhet inte givit upp utan oegennyttigt bisprungit en människa med vilken de officiella organen med bästa vilja inte kunnat komma till rätta.

Utgången av ärendena kunde skifta. Redan att bli omhändertagen kunde ge klienten en tankeställare och övndn inskränkte sig då till att ge en varning och han fick fara sin väg med ett ,gå nu och synda inte mera". Ibland gavs det föreskrifter med avseende å bruket av spritdrycker, avbetalning å skadestånd eller skyldighet att taga arbete eller förbud att utan skyddskonsulentens medgivande byta anställning. Praktiska åtgärder från övndns sida för att hjälpa en misskötsam klient kunde även förekomma. En yngling $\mathrm{E}$ hade fått avbryta utbildningen vid en skogskurs på grund av spritmissbruk. I det fallet uppdrogs det åt ordföranden att förhandla med kursledningen att låta nåd gå före rätt och taga tillbaka E. Enskilda ledamöter åtog sig att söka skaffa rum och arbete åt klienter som inte utan skäl hade svårigheter på detta område. Militära myndigheter kontaktades för att lösa uppkomna svårigheter för klienter i deras egenskap av värnpliktiga. Detta och åtskilligt annat handlades på sammanträden som föranletts av att det börjat gnissla beträffande skyddstillsynen.

Alkoholmissbruket kunde ge anledning till mera vittgående åtgärder än ett mer eller mindre meningslöst förbud att använda sprit. Några fall förtjänar nämnas. $F$ hade utskrivits från en alkoholistanstalt och skulle i omedelbar anslutning härtill få börja en omskolningskurs. Redan under färden från anstalten började $\mathrm{F}$ missbruka sprit och övndn måste låta omhändertaga honom. Vid sammanträdet med övndn fann den efter samtal med F och med ledning av vad som i övrigt blev utrett, att detta icke var något fall med vilket det $\mathrm{i}$ första hand ankom på frivården att taga befattning. Övndn överlämnade $\mathrm{F}$ åt de nykterhetsvårdande myndigheterna att i samråd med läkare vidtaga erforderliga åtgärder. F remitterades efter läkareundersökning till mentalsjukhus och åtgärder vidtogs för återintagning på alkoholistanstalt. En annan man $\mathrm{G}$ hade kommit åtskilligt på sned och måste omhändertagas av övndn. Vid dess sammanträde var ordföranden i den lokala nykterhetsnämnden närvarande och hade fullt klart för sig att den måste ingripa. G fick vara omhänder- 
tagen ytterligare några dagar inom den lagstadgade tiden $\mathrm{i}$ avbidan på resolution om tvångsintagning på alkoholistanstalt.

I de svårare fallen av misskötsamhet och där fråga inte kunde bli om ingripande av nykterhetsvården beslöt övndn att skriva till åklagarmyndigheten och hemställa att denna måtte anhängiggöra talan vid domstol och där yrka antingen att den misskötsamme skulle tagas in på s k skyddsanstalt — där han kunde få sitta en till två månader för att begrunda sin tillvaro och man förberedde hans fortsatta återanpassning - eller att domstolen måtte undanröja skyddstillsynen och förordna om annan påföljd — $\mathrm{t}$ ex fängelse eller ungdomsfängelse. Förfarandet med hänvändelse till åklagarmyndigheten visade sig vara en tungrodd och i de flesta fall verkningslös apparat. Till följd av fördröjd handläggning hos åklagare och domstol blev övndns beslut ofta ett slag i luften. Brottsbalkens uppläggning av denna möjlighet till ändring av påföljd framstod för övndn som föga ändamålsenlig och i behov av översyn.

\section{Övrig verksamhet}

Övndn hölls fortlöpande underrättad om hela sitt klientel vid de genomgångar som befattningshavarna vid frivården gjorde flera gånger om året vid övndns sammanträden. Därvid gick man igenom klient efter klient i övndns kartotek och övndn underrättades om det aktuella läget. Då och då lystes genomgången upp av en liten solskenshistoria och övndn delade då föredragandens glädje över att klienten ,gick bra“. Men då och då dök det upp klienter — icke sällan likt seriefigurer — vilka vållade både frivården och övervakaren bekymmer. Här kunde det bli fråga om ett krafttag från övndns sida och muntlig förhandling med klienten av det slag varom det talats $\mathrm{i}$ det föregående.

Vid såväl dessa genomgångar som andra sammanträden förekom en livlig diskussion och ärendenas handläggning präglades ingalunda av någon rutinmässig eller que-faire-attityd. De olika ledamöternas allmänna läggning återspeglades i deras inställning till uppkomna problem och förslagen till åtgärder. Den domared med däri stadgad tystnadsplikt av vilken ledamöterna i en övndn är bundna lägger hinder i vägen för en närmare redogörelse för vad som förekom under de enskilda överläggningarna. Så mycket kan dock sägas att alla i övndn såg på en gång mänskligt och realistiskt på klientelet och dess problem. Massmedias information och bedömning av svensk kriminalvård följdes med uppmärksamhet. Ett onyanserat klander av kriminalvården härledde man många gånger till bristande insikter i brottslighetens natur och lagskipningens uppgift samt närmare kännedom om de människor det här gällde. Säkerligen skulle det för kritikerna varit upplysande att ha fått tillfälle att se vilket personligt intresse fri- 
vårdens personal och övndns ledamöter visade $\mathrm{i}$ varje särskilt fall och hur man på en gång sökte beaktade klientens och samhällets ofta motstridiga krav.

I det sammanhanget kan nämnas att övndn stundom lade sig ombord med bestyr som författningsenligt måhända låg utanför dess uppgift. Ett exempel härpå är en nådeansökan från en för mord dömd intern. Denna föranledde en i övndns regi verkställd utredning vilken sannolikt ledde till en positiv bedömning av fallet. Samma var förhållandet med ett liknande ärende där övndn fann anledning att upptaga till kritisk granskning vissa händelser vid och efter domfällandet vilka syntes försvåra internens återanpassning och hos honom skapat en inte helt ogrundad bitterhet mot samhället. En till skyddstillsyn dömd, i sprithänseende helt anmärkningsfri klients klart dokumenterade behov av att återfå sitt körkort föranledde demarcher både från övndns och ordförandens sida ända upp till Kungl. Maj:t.

Övndns klientel kunde inte erhålla eller inneha pass för utlandsresa utan övndns medgivande. Bestämmelser saknas om vilka synpunkter som särskilt skall beaktas vid prövning av passfrågorna. Övndn var tämligen sträng vid bedömningen av dessa ärenden och ansåg att $\mathrm{i}$ princip borde den som var underkastad kriminalvård i frihet icke ha pass, särskilt inte unga människor. Som passinnehavare kunde han nämligen genom utlandsresa undraga sig den övervakning som var förbunden med denna form av tillrättaförande och vid behov inte få hjälp och stöd av frivården. Pass medgavs dock för en skötsam elev vid en skola och för en yngling vars familj planerat en gemensam semesterresa. Samma beslut blev det för den som erhållit hyra i utomeuropeisk sjöfart för fortsatt utbildning till maskinbefäl.

Vid övndns besök på ölunda fick internerna framföra önskemål och erinringar mot därvarande förhållanden. Vid ett tillfälle uttalade övndn förståelse för en klagande interns anmärkningar men av praktiska skäl kunde vid den tidpunkten någon rättelse inte åstadkommas utan först senare.

Kanske ger denna skildring av den gren av kriminalvården varom här är fråga en alltför ljus bild av förhållandena även om mörka fläckar här och var inte dolts. Andra övndr har säkerligen haft att taga befattning med ett mera svårbemästrat klientel. Detta i förening med anhopningen av arbetsuppgifterna hos frivårdens befattningshavare kan därför på annat håll ge anledning till andra bedömanden och erfarenheter. Man bör dock ha i minnet att fråga är om en institution som endast stått $i$ begynnelsen av sin verksamhet och att övndn arbetat enligt vad den trott överensstämma med lagstiftarens intentioner och sin tolkning av dessa.

Ernst Leche. 